\title{
Adding value to under-utilised Irish fish roe: a physico- chemical and sensory comparison of cured Irish pollock (Pollachius pollachius) roe with commercial mullet (Mugil cephalus) and cod (Gadus morhua) products
}

A.E. Furey ${ }^{1}$, U. Hoeche ${ }^{1}$, F. Noci' ${ }^{1+}$

${ }^{1}$ Galway Mayo Institute of Technology, Galway, H91 T8NW, Ireland

Abstract

Irish marine fish roe is generally discarded at sea or processed as low value-added fishmeal and not utilised as nutritious seafood ingredients. Locally sourced pollock roes were salted, air-dried (Mediterranean-style) and compared to similar commercial mullet and cod products for: weight; moisture content; $\mathrm{pH}$; instrumental texture and colour; and sensory attributes. Raw pollock roes averaged $105 \mathrm{~g}(n=25)$. Roes lost on average $3.1 \%$ moisture (w/w) after a 2-h salting period and $48.8 \%$ weight reduction was observed after an average $105 \mathrm{~h}$ air-drying time. The moisture content of pollock was not significantly different to commercial products. Average pH for pollock, mullet and cod products was 5.9, 5.4 and 5.7, respectively $(P<0.05)$. Pollock and mullet had similar hardness, but cod was significantly harder than both, when measured instrumentally. Total colour difference ( $\left.\Delta E^{*}\right)$ between the surface of pollock and cod, and that of pollock and mullet was 7.5 and 3.0, respectively. Sensory assessment of sliced and powdered products, using 9-point hedonic and 5-point just-about-right (JAR) scales, was conducted with 38 consumers. Pollock received the highest scores for overall liking and intention to purchase compared to commercial mullet and cod products, averaging 5.6, 5.6 and 4.9, respectively, for sliced roe products, and 6.3, 5.3 and 6.1 for powdered products. Penalty analysis of JAR showed "overall liking" was impacted by the flavour being "too fishy". In conclusion, pollock had similar characteristics and acceptable sensory attributes compared to commercial products presenting opportunities to expand the range of value-added roe products (e.g., trout, salmon) available, while also contributing to waste reduction.

Keywords

Drying $\cdot$ mullet $\cdot$ pollock $\cdot$ roe $\cdot$ sensory

\section{Introduction}

Ireland is an important fishing ground for marine fish including herring (Clupea harengus), cod (Gadus morhua), whiting (Merlangius merlangus), blue whiting (Micromesistius poutassou), ling (Molva molva), hake (Merluccius merluccius), monkfish (Lophius spp), horse mackerel (Trachurus trachurus), plaice (Pleuronectes platessa), pollock (Pollachius pollachius) and sole (Solea solea) (Gerritsen \& Kelly, 2019). Roe is the term for the egg-filled ovaries of a gravid female fish (OECD, 1990). The ovaries of the female fish are generally paired, and either fully or partially fused together (Bond, 1996). Marine fish roes, especially whole fish roes, are not commonly consumed in Ireland and are considered by many, including fishermen, to be a waste product either dumped at sea or processed as fishmeal. This wasted roe can therefore be considered as "marine by-products" (Rustad et al., 2011) of Irish fisheries. Roe is a valuable and important source of marine oils and proteins (Rodrigo et al., 1998; Slizyte et al., 2014). They have nutritionally beneficial long chain omega-3 polyunsaturated fatty acids and antioxidants (Kalogeropoulos et al., 2008, 2012) and therefore could be developed into value-added seafood products that are both nutritious and tasty while contributing to the sustainability and profitability of the Irish fisheries industry.

Many countries produce ready-to-eat food products using both the fully ripe female and male gonads of marine fish (or roe and milt/soft roe). The most common roe product is caviar (Wang et al., 2008). Caviar, traditionally Russian and Iranian, is made by separating and salting the large (2-3.5 $\mathrm{mm}$ ) individual eggs of gravid female sturgeon belonging to the wild and farmed Acipenseridae family including Acipenser, Huso, Pseudoscaphirhynchus and Scaphirhynchus and their hybrid species (Monfort, 2002; FAO, 2013). Other popular substitute-caviar products are made from other species including: trout (Oncorhynchus mykiss), salmon (salmon salar), capelin (Mallotus villosus), lumpfish (Cyclopterus lumpus), paddlefish (Polyodon spathula), catfish (Anarhichas 
spp.) and flying fish (Cheilopogon agoo) (Bledsoe et al., 2003) and are available on the Irish market. Non-caviar style roe products include emulsion spreads common in Scandinavia, where the smaller eggs of cod roe and other white fish $(<0.9$ $1.4 \mathrm{~mm}$ ) are blended with other ingredients including sugar, oil, potato flours and/or cheeses (Bledsoe et al., 2003). Tinned whole milt, from male cod and herring, are found commonly in UK supermarkets (based on market research, data not shown). Other international products include brined whole ovaries from herring, popular in Japan ("Kazunoko") (Shirai et al., 2006). Another whole roe product, which is popular in the Mediterranean and Asia, sees the whole ovary of grey mullet (Mugil cephalus) preserved by dry-salting and airdrying. Known as "bottarga" in Italy, "avgotaracho" in Greece, "poutargue" in France and "karasumi" in Asia (OECD, 1990), these high value products are sold either whole or powdered: and whole roe can retail for as much as approximately $€ 250 /$ $\mathrm{kg}$ (based on market research carried out in 2018, data not shown). Salted air-dried mullet roe has been produced in Europe since the Phoenician era (Monfort, 2002). Bledsoe et al. (2003) described mullet bottarga as having a chewy mouthfeel with a rubbery texture and a yellowish red colour. Whole bottarga is generally consumed either in sliced or grated form; roes not suitable for selling whole are further dehydrated and then powdered and sold in jars or vacuum packed. The powdered form is usually sprinkled on pasta/ pizza as a condiment.

The purpose of this research was to investigate the development of a new seafood product that could potentially add value to under-utilised roe typically found in Ireland's marine environment. Mullet is generally not fished commercially in Irish waters, pollock however, is a common benthopelagic gadoid (Marine Institute, 2019) which is fished in Ireland with fish stocks managed by the European Union (EU) under the Common Fisheries Policy (Marine Institute,
2018). The eggs contained in the roe sack of pollock are small $(<1 \mathrm{~mm})$ and not suitable for the production of caviar style products however, they are suitable for air drying. Pollock roe was processed and compared to commercially available bottarga-style salted air-dried products made from mullet and cod, to examine the similarity and acceptability of its physicochemical and sensory attributes to consumers in Ireland.

\section{Material and methods}

\section{Preparation and dehydration of Pollock material}

Roes $(n=25)$ from Atlantic pollock were obtained and used to produce a salted and air-dried product based on those described by Dimitriou et al. (2016) but amended as follows: paired ovaries from pollock, caught in the Northeast Atlantic in February 2018, were obtained from a local fish monger (frozen and vacuum packed). The whole roes, with outer membrane remaining intact, were defrosted for $18 \mathrm{~h}$ at refrigeration temperature $\left(4^{\circ} \mathrm{C}\right)$, rinsed in fresh water, patted dry and salted for $2 \mathrm{~h}$ using medium-grained food grade sea-salt. The amount of salt used to cure the roe was $3 \%(\mathrm{w} / \mathrm{w})$ of the raw defrosted roe weight. The roes were manually covered in salt by carefully spreading a layer of salt over the entire surface of the roe. After the salting period, the roes were rinsed using fresh water and patted dry. The roes were placed on the middle tray of a food dehydrator (Model No. 4926T, Excalibur, Sacramento, CA, USA), $45 \mathrm{~cm}$ from its air circulation fan with air velocity of $3.0 \mathrm{~m} / \mathrm{s}$. They were dried at ambient average temperature $17.1^{\circ} \mathrm{C}$ and average relative humidity of $62.9 \%$. Drying time ranged from 4 to $7 \mathrm{~d}$ depending on the size of the roe. At the end of the air-drying process, the dried cured pollock roe was firm to the touch and the colour had changed to an amber/ red-brown (Figure 1). The dried pollock roe was vacuum packed (Model No. SE-306, Sammic, Azkoitia, Spain) and
(A)

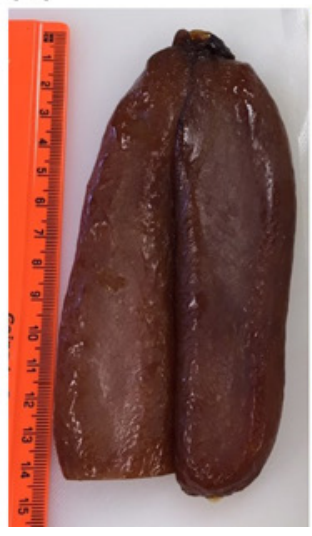

(B)

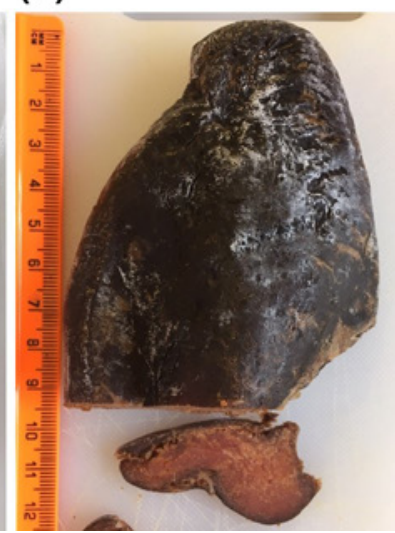

(C)

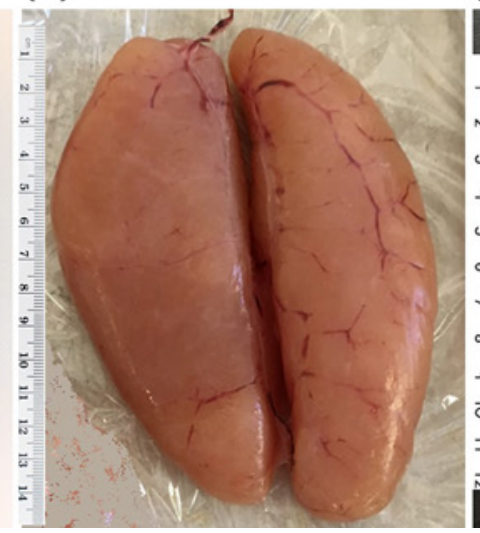

(D)

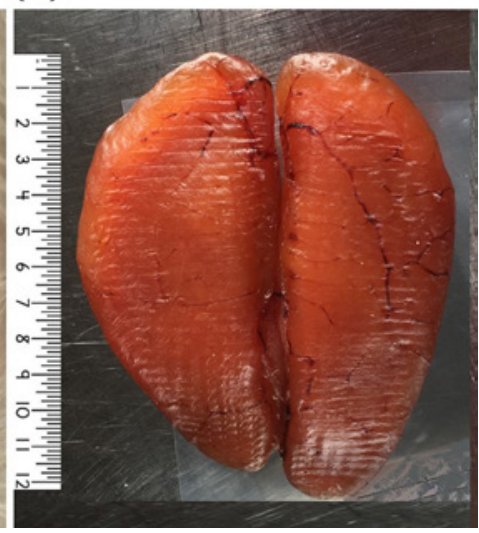

Figure 1. Representative samples of whole roes used: (A) Mullet bottarga from Sardinia (Italy); (B) cod bottarga from Norway; (C) raw ovary from pollock landed in Ireland; (D) salted air-dried pollock roe. 
stored under refrigeration $\left(4^{\circ} \mathrm{C}\right)$. The powdered style product was made by further dehydrating the pollock roe until a $62.0 \%$ average weight reduction was measured. This was observed after a 186-h average drying time. The roes were then cut in to $2 \mathrm{~cm}$ pieces and powdered using a $900 \mathrm{~W}$ food mixer (Model No. SSMP900A1, Hoyer Handel, Hamburg, Germany) for 10 $\mathrm{s}$ at 22,000 rpm and stored in a glass jar. For comparative purposes, mullet bottarga and cod bottarga were purchased in both whole and powdered form from their producers.

\section{Weight and dimensions}

Pollock roes $(n=25)$ were weighed: in their raw state; following the 2-h dry-salting period; and then daily during the air-drying process. The length, width and thickness of the final product was also measured. The length $(L)$ of both ovaries was measured. Three width $(\mathrm{W})$ and thickness $(\mathrm{T})$ measurements were taken on each ovary at approximately $15 \mathrm{~mm}$ from the top and bottom of the ovaries and one at along the central midpoint. Values for average length, width and thickness were then calculated.

\section{Moisture content}

Moisture content of the salted air-dried pollock, commercial mullet and cod products was determined by placing approximately $3 \mathrm{~g}$ of finely chopped sample in an open aluminium foil dish and leaving it in an air oven (BINDER Drying and Heating Chamber, Tuttlingen, Germany) for $24 \mathrm{~h}$ at $100^{\circ} \mathrm{C}$. Moisture analysis was carried out in duplicate and the moisture content was averaged. Moisture content was calculated as the percentage loss in weight of the products (AOAC, 2005).

\section{Colour}

Colour measurements were carried out using a Chroma Meter CR-400 (Konica Minolta Inc., Osaka, Japan) using a CR-A33F glass light projection tube. Absolute values of tristimulus $\mathrm{CIE}$ $L^{*}, a^{*}, b^{*}$ colour scale were used to record lightness, redness and yellowness, respectively, using illuminant $D_{65}$, an $8 \mathrm{~mm}$ aperture and a $0^{\circ}$ viewing angle. Colour difference $(\Delta \mathrm{E})$ was calculated from the difference in colour co-ordinates $\left(L^{*}, a^{*}, b^{*}\right)$ between pollock and mullet; and pollock and cod according to the formula reported in Cserhalmi et al. (2006) (Equation 1). Ten colour measurements were taken along the outer gonad of the roes and the results were averaged (to measure representative external surface colour). The roe was then sliced vertically at the centre of the gonad and three measurements were immediately taken along each exposed cross-sectional slice. The colour of the salted dried pollock was compared with purchased commercial mullet and cod products.

$$
\Delta \mathrm{E}=\sqrt{\left(\Delta \mathrm{L}^{*}\right)^{2}+\left(\Delta \mathrm{a}^{*}\right)^{2}+\left(\Delta \mathrm{b}^{*}\right)^{2}}
$$

\section{pH measurement}

The $\mathrm{pH}$ of salted dried pollock roes was compared with purchased commercial mullet and cod bottarga. The $\mathrm{pH}$ of raw pollock was also measured. Given that the samples were solid foodstuffs, three $5 \mathrm{~g}$ portions of roe were blended for $20 \mathrm{~s}$ at $22,000 \mathrm{rpm}$ in $10 \mathrm{~g}$ of distilled water (using a $900 \mathrm{~W}$ food mixer Model No. SSMP900A1, Hoyer Handel, Hamburg, Germany) to produce a liquid slurry, which represents a modification of the methods used by Çelik et al. (2012), as $10 \mathrm{~mL}$ distilled water was the minimum amount required to achieve a consistency where the $\mathrm{pH}$ probe could be used effectively. The $\mathrm{pH}$ of the resultant slurry was measured using a digital $\mathrm{pH}$ probe $(\mathrm{pH} 150$, Eutech Instruments, Vernon Hills, IL, USA). pH measurements were carried out in triplicate and the results were averaged.

\section{Textural analysis}

In commercial settings, the texture of fish and fish roe products are generally determined by hand where the processor presses gently on the product to determine the right feel (Alasalvar et al., 2001; Caredda et al., 2018). For the purpose of this study, texture profile analysis (TPA), and penetrometer hardness tests were carried out using a TAXT2 texture analyser (Stable Micro Systems, Surrey, UK) equipped with a $25 \mathrm{~kg}$ load-cell, on pollock, mullet and cod dried roe. Three samples from each species were prepared by cutting vertically along the width of the ovary and removing a $1 \mathrm{~cm}$ wide slice. Texture profile analysis was carried using a $50 \mathrm{~mm}$ diameter cylinder probe on a solid support plate, using a speed of $10 \mathrm{~mm} / \mathrm{s}$ and $50 \%$ compression, with a 2-s interval between compressions. Hardness and cohesiveness were measured. Penetrometer tests were also carried out by using a $4 \mathrm{~mm}$ diameter probe and a support plate with a $9 \mathrm{~mm}$ diameter hole, using a speed of $1.0 \mathrm{~mm} / \mathrm{s}$ and a compression depth of $10.0 \mathrm{~mm}$, and hardness was measured.

\section{Sensory evaluation}

Preliminary sensory acceptance tests were carried out, as part of this early stage in food product development, to provide proof of concept and to determine acceptability and degree of liking of the products as well as "just about right" (JAR) assessments of specific attributes (Drake, 2007). Food safety of the pollock product was ensured by performing microbial analysis for ready to eat products by an accredited laboratory. Pathogenic bacteria, as set down in Commission Regulation No 373/2005 (European Commission, 2005), were not detected in the $100 \mathrm{~g}$ pollock product sample analysed. Sensory tests were performed in a suitable food sensory test room in accordance with ISO standards (ISO, 2010). Naïve sensory assessors (ISO, 2014), with no known food allergies, were used as untrained panellists and recruited amongst the student and staff population of the 
Institute. Two separate panels ( $n=38$ each) were used: one to evaluate sliced roe products and a second to evaluate powdered roe products (pollock vs. commercial mullet and cod products). The roe products were removed from refrigerated storage and served on a plain cracker. Whole roes were thinly sliced at a thickness of approx. $1.5 \mathrm{~mm}$, while approx. $0.5 \mathrm{~g}$ of powdered roe was presented to the assessors. Samples were placed in white plastic containers and coded with a 3-digit random number. Assessors were asked to evaluate the degree of liking of each food sample using a 9-point hedonic scale (O'Sullivan, 2016) to determine acceptability of the products based on: appearance, colour, flavour, aroma, texture, mouthfeel and overall liking (1 = dislike extremely; 9 = like extremely). Following hedonic evaluation, the questionnaire had an additional comment box which allowed assessors to add positive and negative comments about the product (Meilgaard et al., 2007). The degree of acceptability of fishiness (fish flavour), saltiness, savouriness, bitterness and acidity was assessed using the bipolar 5-point JAR ordinal scale ( 1 = not nearly enough; $3=$ JAR; 5 = much too) (Gacula et al., 2007), for example, "not nearly fishy enough" to "much too fishy". Penalty analysis was carried out to show the relationship between variables assessed using the JAR scale and overall liking scores (Pagès et al., 2014). The 5-point JAR scale was reduced to a 3-point scale going from "not enough", JAR and "too much". The penalty value was calculated by multiplying the percentage not-JAR ("not enough" or "too much") by the mean decrease in overall liking (Narayanan et al., 2014). A penalty value of $>0.5$ was used to indicate a significant impact on overall liking. Intention to purchase was assessed using a 5 -point Likert scale ( 1 = definitely won't buy; $5=$ definitely will buy). Data were collected using Compusense ${ }^{\circledR}$ Cloud (Guelph, Ontario, Canada) sensory evaluation software.

\section{Statistical analysis}

Statistical differences between groups were determined using one-way analysis of variance (ANOVA) and Tukey's honestly significant difference (HSD) post hoc pairwise comparison tests with IBM ${ }^{\circledast}$ SPSS $^{\circledR}$ Statistics version 24 (New York, NY, USA). A level of $P<0.05$ was used to establish significant differences among means. The independent samples
Kolmogorov-Smirnov test (K-S test) was used to compare the distributions of JAR attributes between species.

\section{Results}

Dehydration of pollock roes: weight loss and dimensions The raw weight of pollock roes $(n=25)$ ranged from 31.1 to $308.8 \mathrm{~g}$ (average $=105.0 \mathrm{~g} \pm 68.5$ ). The variability in the size of roe obtained from the fishmonger reflects the variability in the size and maturity of the wild fish caught at sea. The size of the roe is proportional to the size of the fish. Pollock roes lost on average $3.2 \% \pm 0.7$ moisture $(\mathrm{w} / \mathrm{w})$ after a 2 -h salting period and a total average of $48.8 \% \pm 4.2$ weight reduction was observed after a 104.8-h \pm 31.4 average drying time. Weight and dimensions of the dried products are summarised in Table 1. Commercial dried cod roe differed from the pollock and mullet roe as it was an approximately $100 \mathrm{~g}$ piece excised from one lobe of a dried ovary.

\section{Moisture content}

Table 1 shows an average moisture content for the three species of dried roe. Cured dried pollock had a higher moisture content than both mullet and cod.

\section{Colour}

Average values for colour are shown in Table 2. The external surface of the pollock exhibited highest $L^{*}, a^{*}$ and $b^{*}$ compared to mullet and cod. According to Cserhalmi et al. (2006) classification, the total colour difference $(\Delta \mathrm{E})$ between the external surface of pollock and cod roe could be categorised as "great" while that of pollock and mullet could be categorised as "well visible" $(\Delta \mathrm{E} 7.45$ and 3.02, respectively). There was a significant difference $(P<$ $0.05)$ in internal lightness $\left(L^{*}\right)$ across the species, though pollock roe was not significantly different from either mullet or cod. Colour differences between the internal slice colour of the dried pollock and cod roe $(\Delta \mathrm{E}=4.74)$ and dried pollock and mullet roe $(\Delta \mathrm{E}=$ 4.55): both fell in the category "well visible".

\section{pH measurement}

Average $\mathrm{pH}$ for raw pollock roe was $6.29 \pm 0.05$ decreasing to $5.91 \pm 0.02$ after drying. The $\mathrm{pH}$ of dried pollock versus

Table 1: Weight, dimensions and moisture content of dried roe products ( \pm s.d.)

\begin{tabular}{|c|c|c|c|c|c|c|}
\hline Species & Weight (g) & Length (mm) & Width (mm) & Thickness (mm) & Moisture (\%) & $n$ \\
\hline Pollock & $52.8( \pm 36.7)$ & $91.8( \pm 24.5)$ & $22.1( \pm 8.3)$ & $13.4( \pm 3.6)$ & $34.16( \pm 3.8)^{1}$ & 25 \\
\hline Mullet & $179.0( \pm 158.3)$ & $163.7( \pm 39.4)$ & $31.6( \pm 14.2)$ & $15.1( \pm 4.0)$ & $28.17( \pm 2.1)$ & 4 \\
\hline Cod & $103.3( \pm 2.3)$ & $104.0( \pm 14.3)$ & $47.2( \pm 9.9)$ & $21.7( \pm 4.6)$ & $28.40( \pm 1.3)$ & 3 \\
\hline
\end{tabular}

${ }^{1} n=11$. 
Table 2: Average CIE colour parameter values for whole dried roe products: exterior and interior surfaces $( \pm$ s.d.)

\begin{tabular}{|c|c|c|c|c|c|c|c|}
\hline & & External & & & Internal & & \\
\hline Species & $L^{*}$ & $a^{*}$ & $\mathbf{b}^{*}$ & $L^{*}$ & $a^{*}$ & $\mathbf{b}^{*}$ & $n$ \\
\hline Pollock & $42.95( \pm 3.3)$ & $5.10( \pm 1.8)$ & $7.20( \pm 2.9)$ & $44.95^{\mathrm{ab}}( \pm 4.2)$ & $5.90( \pm 2.2)$ & $8.56( \pm 4.1)$ & 4 \\
\hline Mullet & $41.05( \pm 4.1)$ & $4.13( \pm 2.1)$ & $5.06( \pm 4.1)$ & $41.25^{\mathrm{a}}( \pm 2.0)$ & $7.11( \pm 2.0)$ & $10.92( \pm 3.7)$ & 3 \\
\hline Cod & $41.81( \pm 6.4)$ & $1.81( \pm 0.3)$ & $0.62( \pm 1.3)$ & $49.03^{b}( \pm 1.2)$ & $8.20( \pm 3.6)$ & $12.67( \pm 6.0)$ & 3 \\
\hline$P$-value & 0.845 & 0.076 & 0.550 & 0.025 & 0.518 & 0.757 & \\
\hline
\end{tabular}

Different superscript letters represent significant differences between group means $(P<0.05)$.

commercial mullet and cod products was $5.91 \pm 0.02,5.41 \pm$ 0.00 and $5.74 \pm 0.00$, respectively, and mullet was significantly lower $(P<0.05)$ than both pollock and cod.

\section{Texture analysis}

Table 3 shows hardness results measured with a penetrometer probe and the hardness and cohesiveness values measured by TPA. The instrumental measurement of hardness and cohesiveness for pollock was comparable to that of commercial mullet product $(P>0.05)$ while the cod product had significantly greater hardness $(P<0.05)$. Texture profile analysis for cod could not be measured as samples exceeded the limit of the $25 \mathrm{~kg}$ load cell.

\section{Sensory evaluation of whole sliced products}

The gender distribution of the assessors was $61 \%$ female and $39 \%$ male, ranging in age from 20 to $59 \mathrm{yr}$. Average values for liking of attributes of sliced roe products are shown in Table 4. No significant differences were observed between sliced pollock and mullet for all attributes assessed. Cod was significantly different $(P<0.05)$ in liking of colour, appearance, aroma and mouthfeel and average scores were below 5 for all attributes except flavour. The lowest average score $(3.82 \pm 1.90)$ of all attributes was for mouthfeel of the cod product $(P<0.05)$. In the section dedicated to assessors comments and feedback, $26 \%$ of respondents cited the cod products stickiness to their teeth as a negative (data not shown) and less so with pollock (15\%). The distribution of overall liking is shown in Figure 2 and shows pollock being scored positively (top four liking categories of "like slightly" to "like extremely", hedonic score 6-9) by a cumulative figure of approx. $58 \%$ compared to $55 \%$ and $45 \%$ for mullet and cod products, respectively. The top four responses for liking of flavour (see Figure 3 ) showed positive responses for pollock,

Table 3: Average texture values for dried roe products ( \pm s.d.)

\begin{tabular}{|c|c|c|c|c|}
\hline Species & Penetrometer hardness $(N)$ & TPA hardness $(N)$ & Cohesiveness & $n$ \\
\hline Pollock & $14.49^{\mathrm{a}}( \pm 4.45)^{1}$ & $116.04( \pm 74.95)$ & $0.47( \pm 0.04)$ & 11 \\
\hline Mullet & $14.62^{\mathrm{a}}( \pm 5.22)$ & $126.36( \pm 69.69)$ & $0.43( \pm 0.11)$ & 4 \\
\hline Cod & $70.02^{b}( \pm 25.76)$ & - & - & 3 \\
\hline$P$-value & 0.000 & & & \\
\hline
\end{tabular}

See footnote to Table 2 . TPA = texture profile analysis.

${ }^{1} n=15$.

Table 4: Average values for acceptance of attributes of sliced dried roe - 9-point hedonic scale ( \pm s.d.)

\begin{tabular}{lcllc}
\hline Attribute & Pollock & Mullet & Cod & $P$-value \\
\hline Colour & $6.42^{\mathrm{a}}( \pm 1.50)$ & $6.26^{\mathrm{a}}( \pm 1.48)$ & $4.79^{\mathrm{b}}( \pm 1.77)$ & $4.97^{\mathrm{b}}( \pm 1.95)$ \\
Appearance & $6.79^{\mathrm{a}}( \pm 1.44)$ & $6.45^{\mathrm{a}}( \pm 1.45)$ & $4.82^{\mathrm{a}}( \pm 1.87)$ & 0.00 \\
Texture & $5.53^{\mathrm{a}}( \pm 1.70)$ & $5.74^{\mathrm{a}}( \pm 1.52)$ & $4.42^{\mathrm{b}}( \pm 1.88)$ & 0.05 \\
Aroma & $5.71^{\mathrm{a}}( \pm 1.63)$ & $5.42^{\mathrm{a}}( \pm 1.31)$ & $5.55( \pm 2.17)$ & 0.00 \\
Flavour & $5.66( \pm 1.71)$ & $5.58( \pm 2.00)$ & $3.82^{\mathrm{b}}( \pm 1.90)$ & 0.97 \\
Mouthfeel & $5.13^{\mathrm{a}}( \pm 1.86)$ & $5.55^{\mathrm{a}}( \pm 2.00)$ & $4.89( \pm 1.86)$ & 0.00 \\
Overall liking & $5.58( \pm 1.72)$ & $5.61( \pm 1.81)$ & & 0.15 \\
\hline
\end{tabular}

See footnote to Table 2. 


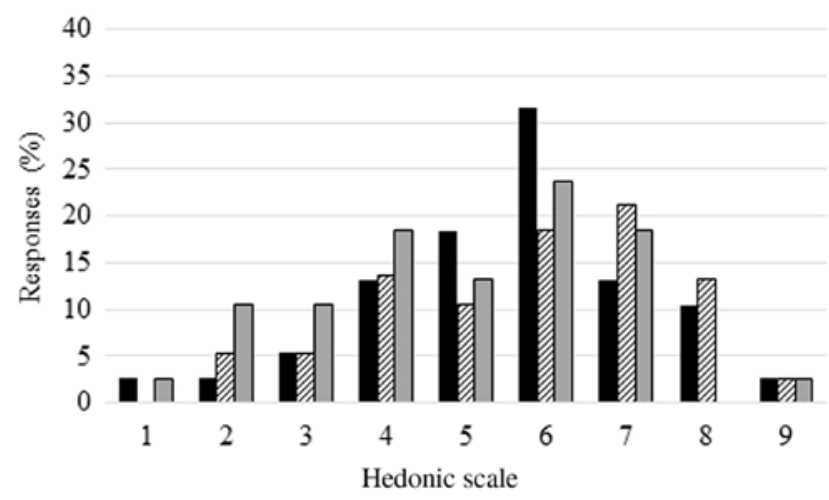

Figure 2. Percentage distribution of responses for overall liking of sliced roe products: pollock ( $\square$ ), mullet (圈), cod ( $\square$ ). (Hedonic scale: 1 = dislike extremely; 2 = dislike very much; 3 = dislike moderately; 4 = dislike slightly; 5 = neither like nor dislike; 6 = like slightly; 7 = like moderately; 8 = like very much; 9 = like extremely).

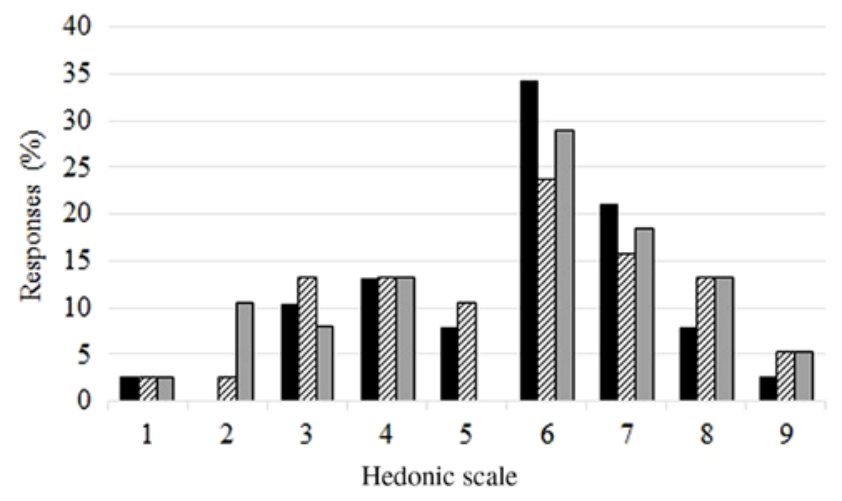

Figure 3. Percentage distribution of responses for liking of flavour of sliced roe products: pollock ( $\square)$, mullet (四), cod ( $\square$ ). (Hedonic scale: 1 = dislike extremely; 2 = dislike very much; 3 = dislike moderately; 4 = dislike slightly; 5 = neither like nor dislike; 6 = like slightly; 7 = like moderately; 8 = like very much; 9 = like extremely).

mullet and cod products with cumulative percentages of $66 \%, 58 \%$ and $66 \%$, respectively. The top three intention to purchase responses (3-5 on the Likert scale) for sliced pollock, mullet and cod products was approx. $66 \%, 55 \%$ and $45 \%$, respectively.

The percentage distribution of 3-point JAR evaluations for the three sliced roe products are presented in Table 5. K-S tests showed the distribution of JAR attributes was similar between roe samples, except for the distribution of saltiness between cod and mullet which was significantly different $(P<$ 0.05). Penalty analysis of JAR attributes (Table 6 ) showed that perception of fishiness had a high impact on overall liking, as assessors penalised both mullet and cod products when "too much" fishiness was perceived (penalty $>0.5$ ).

\section{Sensory evaluation of powdered products}

The gender distribution of assessors was 58\% female, 37\% male and $5 \%$ would rather not disclose, ranging in age from 18 to 59 years. Average values for liking of attributes of powdered roe products are shown in Table 7 . Significant differences $(P<0.05)$ were observed between products for all attributes except for texture. Cod was significantly different to pollock and mullet $(P<0.05)$, scoring lower for colour, appearance and aroma. Mullet was significantly different for flavour, mouthfeel and overall liking $(P<0.05)$.

The distribution of overall liking responses is presented in Figure 4. The top four cumulative overall liking responses ("like slightly" to "like extremely", hedonic score 6-9) for pollock, mullet and cod was $76 \%, 55 \%$ and $76 \%$, respectively, when offered in powdered form. All three products were commented on positively for colour and appearance and negatively for texture (powdery) and aroma/flavour (too fishy); mullet received negative comments for bitterness. The distribution of responses for acceptance of flavour are shown in Figure 5. The top four cumulative positive responses for liking of flavour of pollock, mullet and cod products was $79 \%, 55 \%$ and $68 \%$, respectively. The top three cumulative responses (3-5 on the Likert scale) for intention to purchase of powdered pollock, mullet and cod products was $66 \%, 47 \%$ and $58 \%$, respectively.

The percentage distribution of 3-point JAR evaluations for the powdered roe products are presented in Table 5 . K-S tests showed that the distribution of JAR attributes was similar between roe samples, except for the distribution of fishiness between pollock and mullet which was significantly different $(P$ $<0.05$ ). Penalty analysis of JAR attributes (Table 6) showed that perception of fishiness had a high impact on overall liking, as assessors penalised both mullet and cod products when "too much" fishiness was perceived (penalty $>0.5$ ).

\section{Discussion}

The purpose of this study was to manufacture a new salted dried roe product using pollock, investigate its characteristics and compare it to commercially available roe products, with a view to potentially adding value to under-utilised roe in Ireland. The pollock roe varied in size and weight and represents the variability of wild fish caught at sea. The commercial cured roes purchased were the product of a more standardised process with far less variability. The weights of raw pollock roe used to produce salted dried roe were typically smaller than those used in commercial "bottarga" manufacturing where mullet roe ranged between 251 and $354 \mathrm{~g}$ (Caredda et al., 2018). Cod roes are generally much larger than those from pollock and mullet and typically weigh $10 \%$ of the total whole fish weight (Bannerman, 2000) which can range from less than $1 \mathrm{~kg}$ to over 
Table 5: Percentage distribution of JAR and not JAR responses for sliced and powdered roe products (3-point scale ${ }^{1}$ )

\begin{tabular}{llccccc}
\hline & \multicolumn{3}{c}{ Sliced roe } & \multicolumn{3}{c}{ Powdered roe } \\
\hline Attribute & Pollock & Mullet & Cod & Pollock & Mullet & Cod \\
\hline Fishiness & $(16) 61(24)$ & $(13) 53(34)$ & $(0) 47(53)$ & $(13) 61(26)$ & $(5) 32(63)$ & $(13) 50(37)$ \\
Saltiness & $(26) 42(32)$ & $(24) 58(18)$ & $(18) 32(50)$ & $(18) 68(13)$ & $(11) 50(39)$ & $(26) 58(16)$ \\
Savouriness & $(11) 84(5)$ & $(18) 68(13)$ & $(29) 53(18)$ & $(11) 82(8)$ & $(8) 79(13)$ & $(24) 71(5)$ \\
Bitterness & $(11) 63(26)$ & $(16) 53(32)$ & $(21) 55(24)$ & $(16) 71(13)$ & $(21) 50(29)$ & $(21) 68(11)$ \\
Acidity & $(24) 58(18)$ & $(26) 47(26)$ & $(29) 68(3)$ & $(16) 74(11)$ & $(21) 71(8)$ & $(29) 68(3)$ \\
\hline
\end{tabular}

13-point scale: (not enough) just-about-right (JAR) (too much). Highest JAR score highlighted in bold.

Table 6: Penalty values of not JAR attributes for sliced and powdered roe products

\begin{tabular}{|c|c|c|c|c|c|c|c|c|c|c|c|c|}
\hline \multirow[b]{3}{*}{ Attribute } & \multicolumn{6}{|c|}{ Sliced roe } & \multicolumn{6}{|c|}{ Powdered roe } \\
\hline & \multicolumn{2}{|c|}{ Pollock } & \multicolumn{2}{|c|}{ Mullet } & \multicolumn{2}{|c|}{ Cod } & \multicolumn{2}{|c|}{ Pollock } & \multicolumn{2}{|c|}{ Mullet } & \multicolumn{2}{|c|}{ Cod } \\
\hline & NE & TM & NE & TM & NE & TM & NE & TM & NE & TM & NE & TM \\
\hline Fishiness & 0.3 & 0.3 & 0.2 & 0.6 & 0.0 & 0.7 & 0.0 & 0.5 & 0.0 & 1.3 & 0.0 & 0.5 \\
\hline Saltiness & 0.3 & 0.1 & 0.4 & 0.1 & 0.1 & 0.4 & 0.0 & 0.1 & 0.1 & 0.1 & 0.0 & 0.1 \\
\hline Savouriness & 0.0 & 0.1 & 0.4 & 0.2 & 0.3 & 0.0 & 0.1 & 0.0 & 0.3 & 0.3 & 0.1 & -0.1 \\
\hline Bitterness & 0.1 & 0.2 & 0.1 & 0.5 & -0.2 & -0.2 & 0.0 & 0.1 & 0.2 & 0.4 & -0.1 & -0.1 \\
\hline Acidity & 0.2 & 0.3 & 0.3 & 0.3 & -0.1 & 0.1 & 0.0 & 0.1 & 0.0 & 0.1 & -0.2 & 0.0 \\
\hline
\end{tabular}

JAR = just-about-right; NE = not enough; $\mathrm{TM}=$ too much.

$>0.5=$ high impact on liking (highlighted bold); $>0.25-<0.5=$ potential impact on liking; $<0.25=$ low impact on liking.

Table 7: Average values for acceptance of powdered roe attributes, 9-point hedonic scale ( \pm s.d.)

\begin{tabular}{lcccc}
\hline Attribute & Pollock & Mullet & Cod & $P$-value \\
\hline Colour & $6.21^{\mathrm{ab}}( \pm 1.53)$ & $6.84^{\mathrm{a}}( \pm 1.53)$ & $5.50^{\mathrm{b}}( \pm 1.47)$ & 0.00 \\
Appearance & $6.26^{\mathrm{a}}( \pm 1.33)$ & $6.50^{\mathrm{a}}( \pm 1.56)$ & $5.29^{\mathrm{b}}( \pm 1.45)$ & 0.00 \\
Texture & $6.13^{( \pm 1.28)}$ & $5.58( \pm 1.55)$ & $5.50( \pm 1.48)$ & 0.12 \\
Aroma & $5.71^{\mathrm{a}}( \pm 1.81)$ & $4.87^{\mathrm{ab}}( \pm 1.66)$ & $4.61^{\mathrm{b}}( \pm 1.97)$ & 0.02 \\
Flavour & $6.32^{\mathrm{a}}( \pm 1.95)$ & $5.00^{\mathrm{b}}( \pm 2.01)$ & $6.08^{\mathrm{a}}( \pm 1.78)$ & 0.01 \\
Mouthfeel & $6.13^{\mathrm{a}}( \pm 1.44)$ & $5.21^{\mathrm{b}}( \pm 1.65)$ & $5.71^{\mathrm{ab}}( \pm 1.49)$ & 0.03 \\
Overall liking & $6.26^{\mathrm{a}}( \pm 1.69)$ & $5.29^{\mathrm{b}}( \pm 1.80)$ & $6.11^{\mathrm{ab}}( \pm 1.25)$ & 0.02 \\
\hline
\end{tabular}

See footnote to Table 2.

$13 \mathrm{~kg}$ (Marine Institute, 2019). The width and thickness of the final dried pollock roe products was comparable to that of some commercially available mullet roe. The moisture content of commercial products was in line with moisture content of mullet reported by Çelik et al. (2012), who showed average moisture of $26.3 \%$ and Caredda et al. (2018) showing values ranging from 22.4 to $31.4 \%$. Pollock moisture values in the current study were more in line with those reported by Bledsoe et al. (2003) of $30.5 \%$ for salted dried mullet roe and Greek mullet roe (45.1\%) in a study by Kalogeropoulos et al. (2008).
Colour is an important attribute which influences food choice and acceptability (Paakki et al., 2016). While noticeable colour differences $(\Delta \mathrm{E})$ were observed between pollock and other species, the sensory assessment showed a positive liking of colour and appearance of both pollock and mullet roe compared to that of cod, as sliced pollock and powdered mullet received the highest average scores. Positive comments confirmed consumers' liking of the colour of pollock and mullet when received in both sliced and powdered form. 


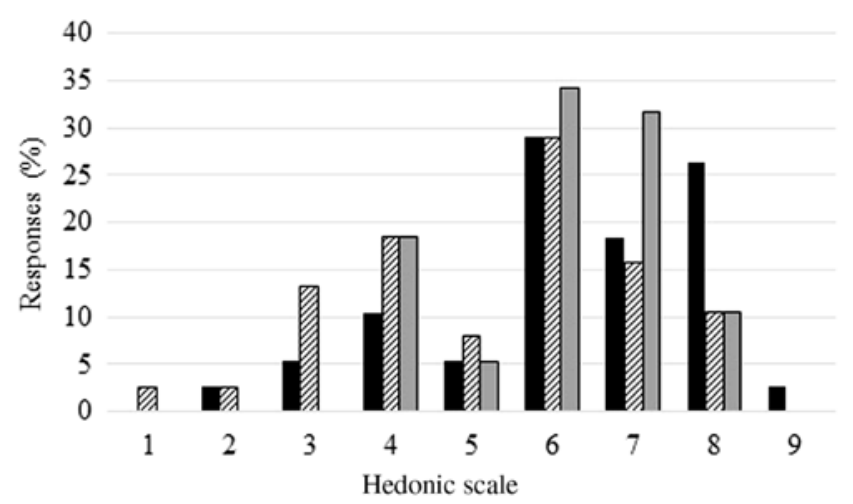

Figure 4. Percentage distribution of responses for overall liking of

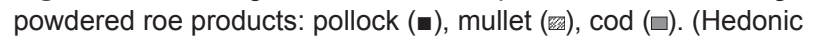
scale: 1 = dislike extremely; 2 = dislike very much; 3 = dislike moderately; 4 = dislike slightly; 5 = neither like nor dislike; 6 = like slightly; 7 = like moderately; 8 = like very much; 9 = like extremely).

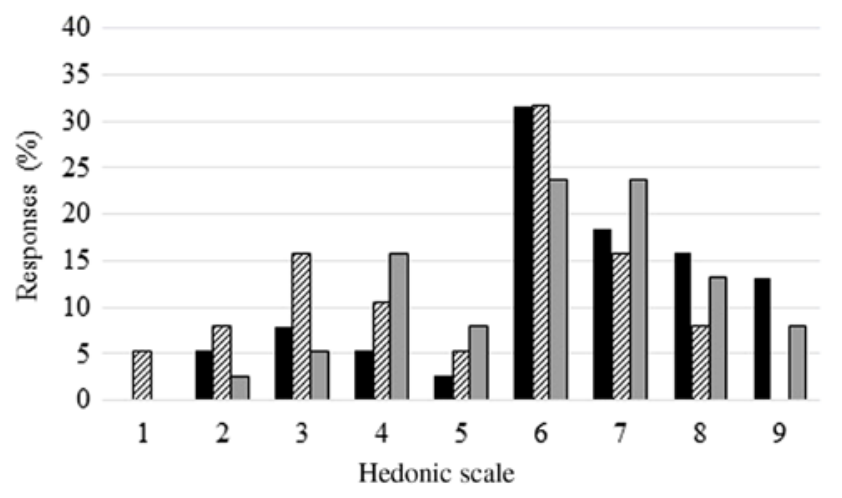

Figure 5. Percentage distribution of responses for liking of flavour of powdered roe products: pollock $(\square)$, mullet (国), cod $(\square)$. (Hedonic scale: 1 = dislike extremely; 2 = dislike very much; 3 = dislike moderately; 4 = dislike slightly; 5 = neither like nor dislike; 6 = like slightly; 7 = like moderately; 8 = like very much; 9 = like extremely).

The $\mathrm{pH}$ of dried pollock was similar to the commercial cod product. Salted dried mullet showed variability in other studies: Caredda et al. (2018) reported an average $\mathrm{pH}$ of 5.96 in raw mullet roe decreasing to 5.88 over the drying period, while an average $\mathrm{pH}$ of 5.60 for dried mullet was reported by Barra et al. (2008), who also observed that Sardinian bottarga made using local mullet had an average $\mathrm{pH}$ of 5.30 . Both pollock and cod are from the Gadidae family (Bond, 1996) which may partially account for the similarity in the $\mathrm{pH}$ values observed. Sliced pollock roe compared favourably with mullet and differed significantly from cod for most attributes except for flavour and overall liking. Significant differences in the evaluation of cod samples were mainly attributable to visual, tactile and olfactory cues prior to consumption. This is in line with colour differences $(\Delta \mathrm{E})$ and hardness differences measured instrumentally. All attributes evaluated while chewing the samples showed no differences across the three products, with the exception of mouthfeel. The sensory evaluation of sliced products showed similar average values of acceptance of pollock and mullet texture while the texture of cod had a lower value of acceptance. When looking at results for acceptance of mouthfeel, a similar trend was observed as cod scored the lowest. This result can be attributable to the products tendency to stick to teeth when chewed in sliced form, rather than uniquely an effect of product hardness. In comparison, when products were sampled in powdered form any effect of hardness was removed and reduced the chewy/ stickiness of the product which contributed to the higher mouthfeel-liking scores for pollock over both mullet and cod. Penalty analysis showed that impact of fishiness on overall liking was greatest in the cod sample (0.72) and decreased to 0.59 and 0.3 in mullet and pollock, respectively. This result would support the differences observed in the liking of aroma, possibly indicating that the stronger the fishy aroma of the sample, the lower the aroma scores. The level of saltiness in all products had the potential to impact liking while the level of bitterness in mullet had the potential to impact overall liking, highlighting the need for accurate monitoring of process and product parameters during the manufacturing and storage of dried roe.

The distribution of flavour and overall liking for all sliced and powdered roe products showed a greater proportion of assessors responding in the "like slightly" to "like extremely" categories, indicating an overall positive response to the products. K-S tests showed that pollock, when compared to both commercial mullet and cod products, had similar distributions in JAR responses regardless of being presented as sliced or powdered. The intention to purchase responses also confirmed a positive attitude towards the pollock roe products.

There were significant differences in liking of attributes across all products when sampled in powdered form, except for texture. This was to be expected as the samples were served in powdered form and their main distinctive texture characteristics had been removed. Pollock was comparable with mullet for visual and olfactory cues (appearance, colour and aroma) and scored higher than cod for the same attributes. However, pollock was comparable to cod for flavour, mouthfeel and overall liking but was scored higher than mullet for the same attributes. Negative comments for all three products confirmed assessors dislike of fishiness and dry/powdery texture with mullet having the most negative references to fishy aroma and taste. Penalty analysis correlated well with the negative comments, as overall liking of mullet and cod products were penalised for "too much" fishiness. Similar to the assessment of sliced mullet, "too much" bitterness had 
a potentially negative impact on the overall liking of mullet. Although manufactured through a highly consistent process, the fact that roe products are manufactured using wild marine fish with inherent natural variability in many factors (e.g., roe maturity, environmental factors, feeding history, harvesting, post-harvesting, processing and storage) could affect the organoleptic properties of fish (Grigorakis, 2007), resulting in differences in liking. However, as the manufacturing of commercial powdered roe products is dependent on very controllable processing parameters (including degree of dehydration, mechanical grating to produce a powdered product) and blending of roe powders, the variability of raw material is less likely to impact on the organoleptic properties of the powdered product. While the pollock was manufactured and used for sensory assessment within $1 \mathrm{wk}$, the commercial products were purchased within their shelf life but they were not purchased immediately after production. According to Rosa et al. (2012), the storage of mullet bottarga caused oxidation of the lipid fraction and a darkening of colour caused by the effects of storage temperature, exposure to light, protein-lipid interactions and protein-sugar interactions. The very dark colour of the cod roe is likely to be the result of non-enzymatic browning arising from the production and storage procedures adopted by the manufacturer (dehydration time known to be outdoors for a period of $15 \mathrm{wk}$ but unknown salting, temperature and light exposure processes). The mullet and cod roe products used for this experiment had a total lipid content of $24.6 \%$ and $2.6 \%$, respectively. Increased levels of free fatty acid from lipid hydrolysis was observed by Rosa et al. (2009) during the curing process of mullet bottarga and by Lapa et al. (2011) for processed cod roe during production of cod roe paste. Powdered bottarga was found to be more susceptible to lipid oxidation due to its increased surface area (Rosa et al. 2009). A review of negative comments for powdered mullet indicated consumers found the powdered form to be very fishy in aroma and flavour. It is therefore possible that the powdered mullet was more prone to lipid oxidation than the cod. In contrast, comments regarding disliking of powdered cod was spread between flavour, texture and colour of the product. Comments from consumers regarding the disliking of pollock were more related to texture rather than flavour. Overall, the pollock received favourable scores compared to the commercial mullet and cod products.

\section{Conclusion}

Salted air-dried roe is not a widely consumed food product in Ireland. Roe from marine fish landed in Ireland is currently not processed further for products of this kind. The comparison of salted dried pollock roe (manufactured for this study) with commercially available mullet and cod bottarga-style products indicated similar physico-chemical characteristics and positive sensory acceptance. Sensory assessment indicated that the effect of serving the product in powdered form positively affected the overall acceptance of the pollock and cod products. The results also indicated a preference of pollock compared to the commercially available mullet and cod products and that perceived fishiness particularly impacted overall liking of products. These results suggest the development of products from pollock roe could offer a viable opportunity to add value to this fish. It also presents further opportunities to expand on a range of value-added products made using other marine and freshwater fish species caught and sold in Ireland, as well as contributing to waste reduction in the Irish fishing sector.

\section{Acknowledgements}

This work was supported by the Galway Mayo Institute of Technology Research \& Innovation Strategic Endowment (RISE) Scholarship. The authors would like to thank the participants of the sensory tests.

\section{References}

Alasalvar, C., Taylor, K.D.A., Öksüz, A., Garthwaite, T., Alexis, M.N. and Grigorakis, K. 2001. Freshness assessment of cultured sea bream (Sparus aurata) by chemical, physical and sensory methods. Food Chemistry 72: 33-40.

AOAC. 2005. "Official Methods of Analysis of AOAC International", 18th Edition, AOAC, Maryland.

Bannerman, A.M. 2000. Processing cod roes. In: "Tory Advisory Notes", H.M.S.O. Press, Edinburgh.

Barra, A., Garau, V.L., Dessi, S., Sarais, G., Cereti, E., Arlorio, M., Coisson, J.D. and Cabras, P. 2008. Chemical characterization and DNA tracking of Sardinian botargo by Mugil cephalus from different geographical origins. Journal of Agricultural and Food Chemistry 56: 10847-10852.

Bledsoe, G.E., Bledsoe, C.D. and Rasco, B. 2003. Caviars and fish roe products. Critical Reviews in Food Science Nutrition 43: 233271. Available online: https://www.aboutseafood.com/sites/all/ files/S-292.pdf.

Bond, C.E. 1996. "Biology of Fishes", 2nd Edition, Saunders College Pub., Fort Wort, 750 pages.

Caredda, M., Addis, M., Pes, M., Fois, N., Sanna, G., Piredda, G. and Sanna, G. 2018. Physico-chemical, colorimetric, rheological parameters and chemometric discrimination of the origin of Mugil cephalus' roes during the manufacturing process of Bottarga. Food Research International 108: 128-135.

Çelik, U., Altinelataman, C., Dinçer, T. and Acarh, D. 2012. Comparison of fresh and dried flathead grey mullet (Mugil cephalus, Linnaeus 1758) caviar by means of proximate composition and quality 
changes during refrigerated storage at $4 \pm 2^{\circ} \mathrm{C}$. Journal of Fisheries and Aquatic Sciences 12: 1-5.

Cserhalmi, Z., Sass-Kiss, Á., Tóth-Markus, M. and Lechner, N. 2006. Study of pulsed electric field treated citrus juices. Innovative Food Science and Emerging Technologies 7: 49-54.

Dimitriou, E., Katselis, G., Moutopoulos, D.K., Milios, K., Malamis, A. and Koutsikopoulos, C. 2016. Description of the processing stages of a protected designation of origin fish product: The Greek caviar "avgotaracho Messolongiou". Agricultural Economics Review 17: 50-62.

Drake, M.A. 2007. Invited Review: sensory analysis of dairy foods. American Dairy Science Association 90: 4925-4937.

European Commission. 2005. "Commission Regulation (EC) No 2073/2005 of 15 November 2005 on Microbiological Criteria for Foodstuffs", European Commission, Brussels, EC.

FAO. 2013. "Standard For Sturgeon Caviar: CODEX STAN 291 - 2010" [Online]. FAO. Available online: http:// www.fao.org/fao-who-codexalimentarius/sh-proxy/ zh/?lnk=1\&url=https $\% 253$ A $\% 252 F \% 252 F$ workspace.fao.org $\% 25$ 2Fsites\%252Fcodex\%252FStandards\%252FCODEX\%2BSTAN \%2B291-2010\%252FCXS_291e_2013.pdf [Accessed 28 March 2018], 4 pages.

Gacula, M., Rutenbeck, S., Pollack, L., Resurreccion, A.V.A. and Moskowitz, H.R. 2007. The just-about-right intensity scale: functional analyses and relation to hedonics. Journal of Sensory Studies 22: 194-211.

Gerritsen, H.D. and Kelly, E. 2019. "Atlas Of Commercial Fisheries Around Ireland", 3rd Edition, Marine Institute Ireland, Galway.

Grigorakis, K. 2007. Compositional and organoleptic quality of farmed and wild gilthead sea bream (Sparus aurata) and sea bass (Dicentrarchus labrax) and factors affecting it: a review. Aquaculture 272: 55-57.

ISO. 2010. "ISO 8589:2010+A1 Sensory Analysis - General Guidance for the Design of Test Rooms". International Organization for Standardization, Geneva.

ISO. 2014. "8586:2014 Sensory Analysis - General Guidelines for the Selection, Training and Monitoring of Selected Assessors and Expert Sensory Assessors". International Organization for Standardization, Geneva.

Kalogeropoulos, N., Nomikos, T., Chiou, A., Fragopoulou, E. and Antonopoulou, S. 2008. Chemical composition of Greek avgotaracho prepared from mullet (Mugil cephalus): nutritional and health benefits. Journal of Agriculture and Food Chemistry 56: 5916-5925.

Kalogeropoulos, N., Mikellidi, A., Nomikos, T. and Chiou, A. 2012. Screening of macro- and bioactive microconstituents of commercial finfish and sea urchin eggs. LWT - Food Science and Technology 46: 525-531.

Lapa-Guimarães, J., Trattner, S. and Pickova, J. 2011. Effect of processing on amine formation and the lipid profile of cod (Gadus morhua) roe. Food Chemistry 129: 716-723.
Marine Institute. 2018. "Irelands Marine Atlas" [Online]. Marine Institute Ireland. Available online: http://atlas.marine.ie/\#?c=53.9043:15.9082:6.

Marine Institute. 2019. "Species Dashboard" [Online]. Marine Institute Ireland. Available online: https://shiny.marine.ie/speciesdash/.

Meilgaard, M.C., Civille, G.V. and Carr, T.B. 2007. "Sensory Evaluation Techniques". CRC Press, Florida, 448 pages.

Monfort, M.C. 2002. Fish roe in Europe: supply and demand conditions. FAO/GLOBEFISH Research Programme 72: 47.

Narayanan, P., Chinnasamy, B., Jin, L. and Clark, S. 2014. Use of justabout-right scales and penalty analysis to determine appropriate concentrations of stevia sweeteners for vanilla yoghurt. Journal of Dairy Science 97: 3262-3272.

O'Sullivan, M. 2016. "A Handbook for Sensory and Consumer-Driven New Product Development: Innovative Technologies for the Food and Beverage Industry". Woodhead Publishing, London, 370 pages.

OECD. 1990. "Multilingual Dictionary of Fish and Fish Products = Dictionnaire multilingue des poissons et produits de la pêche". Organisation for Economic Co-operation and Development, Oxford.

Paakki, M., Sandell, M. and Hopia, A. 2016. Consumer's reactions to natural, atypically colored foods: an investigation using blue potatoes. Journal of Sensory Studies 31: 78-89.

Pagès, J., Berthelo, S., Brossier, M. and Gourret, D. 2014. Statistical penalty analysis. Food Quality and Preference 32: 16-23.

Rodrigo, J., Ros, G., Periago, M.J., López, C. and Ortuño, J. 1998. Proximate and mineral composition of dried salted roes of hake (Merluccius merluccius, L.) and ling (Molva molva, L.). Food Chemistry 63: 221-225.

Rosa, A., Scano, P., Melis, M.P., Deiana, M., Atzeri, A. and Dessí, M.A. 2009. Oxidative stability of lipid components of mullet (Mugil cephalus) roe and its product "bottarga". Food Chemistry 115: 891-896.

Rosa, A., Scano, P., Atzeri, A., Deiana, M., Mereu, S. and Dessi, A.M. 2012. Effect of storage conditions on lipid components and color of Mugil cephalus processed roes. Journal of Food Science 71: 107-114.

Rustad, T., Storro, I. and Slizyte, R. 2011. Possibilities for the utilisation of marine by-products. International Journal of Food Science \& Technology 46: 2001-2014.

Shirai, N., Higuchi, T. and Suzuki, H. 2006. Effect of lipids extracted from a salted herring roe food product on maze-behavior in mice. Journal of Nutritional Science and Vitaminology 52: 451-456.

Slizyte, R., Carvajal, A.K., Mozuraityte, R., Aursand, M. and Storro, I. 2014. Nutritionally rich marine proteins from fresh herring byproducts for human consumption. Process Biochemistry 49: 1205-1215.

Wang, Q., Xue, C.H., Li, Z.J. and Xu, J. 2008. Phosphatidylcholine levels and their fatty acid compositions in squid egg: a comparison study with pollack roe and sturgeon caviar. Journal of Food Lipids 15: 222-230. 